\title{
Karyotype and Idiogram of Jayawadagi Goats of Karnataka
}

\author{
Basavraj Inamdar $^{1 *}$, R. Nagaraja ${ }^{2}$, S. Naveen Kumar ${ }^{1}$, H. M. Yathish ${ }^{1}$, \\ G. S. Naveen Kumar ${ }^{3}$, K. V. Sudha ${ }^{4}$ and S. Rashmi ${ }^{5}$ \\ ${ }^{1}$ Department of Animal Genetics and Breeding, Veterinary College, KVAFSU, Hebbal, \\ Bengaluru -560024, Karnataka, India \\ ${ }^{2}$ Veterinary College, KVAFSU, Gadag -582 101, Karnataka, India \\ ${ }^{3}$ Veterinary College, KVAFSU, Hassan- 573 202, Karnataka, India \\ ${ }^{4}$ Department of Food Science and Nutrition, College of Community Science, University of \\ Agricultural Sciences, Dharwad - 580001, Karnataka, India \\ ${ }^{5}$ Genetic Disorders Screening Scheme, SRDDL, IAHVB, KVAFSU, Hebbal, Bengaluru - \\ 560024, Karnataka, India \\ *Corresponding author
}

\section{A B S T R A C T}

Keywords

Jayawadagi,

Cytogenetic,

Karyotype,

Chromosome

Article Info

Accepted:

22 June 2020

Available Online:

10 July 2020
The study was conducted to karyotype and prepare idiogram of Jayawadagi goats. Blood samples for short term lymphocyte culture were collected from 5 male and 5 female Jayawadagi goats. The diploid chromosome number was found to be 60 , consisting of 29 pairs of acrocentric autosomes and a pair of allosomes ( $\mathrm{X}$ and $\mathrm{Y}$ ). The $\mathrm{X}$ chromosome was the longest acrocentric and $\mathrm{Y}$ chromosome was found to be sub metacentric. The mean mitotic drive was $57.95 \pm 1.16$ and $60.2 \pm 2.38$ per cent in males and females, respectively. The mean relative length of autosome varied from $1.81 \pm 0.08$ to $4.79 \pm 0.09$ in females and $1.46 \pm 0.17$ to $4.11 \pm 0.44$ in males. The relative length of $\mathrm{X}$ - chromosome in females was $5.24 \pm 0.19$ and that in males was $4.13 \pm 0.63$, whereas $Y$ - chromosome had a relative length of $1.40 \pm 0.24$. The mean values of Arms ratio, Centromeric Index and Morphological Index was $3.09,30.00$ and 712.49, respectively. This karyological study indicated the normal chromosomal complement in studied Jayawadagi goats.

\section{Introduction}

Goat farming provides livelihood to millions of marginal and landless laborers. It offers much needed income generation for sustenance of rural backward communities and act as traditional occupation for most of them. The goat population in India is 148.88 million in 2019 and shown an increase by 10.1 per cent over the previous census of 
2012 (Anon., 2019). India has 34 registered goat breeds and many non-descript goats which have high potentialities and yet to be characterized. In Karnataka, there has been continuous increase in goat population and reached 6.17 million in 2019 (Anon., 2019).

Jayawadagi goats are well adapted to local production conditions and environment. These are generally hardy, survive and reproduce on low plane of nutrition and require minimal inputs with regard to their management. Characterization of these goats is essential to harness the associated genetic potentialities to meet the ever growing demand for their products. Karyological characterization has significant role in identifying the breed and forms the basis for molecular genetic characterization (Ekambaram et al., 2011). It enables correct identification of individual chromosomes and establishes standard karyotype, which is essential for breed characterization (Stranzinger and Fechheimer, 1989). Cytogenetic studies help in selection of animals free from chromosome abnormalities (abnormal body conformation, lower fertility or sterility). The chromosomal profiling will act as useful tool to evaluate reproductive health and fertility status of breeding animals at very early age (Basumantary 2003). Keeping this in view the technique of short term lymphocyte culture for Jayawadagi goats was standardized and various morphometric measurements of chromosomes and idiogram were established.

\section{Materials and Methods}

\section{Identification of animals}

This study was conducted on Jayawadagi goats maintained by farmers in their breeding tract. Total of 10 goats $(5$ males and 5 females) were identified randomly from the breeding population for karyological studies.

\section{Blood collection}

Blood samples were collected from the jugular vein of 5 males and 5 females using heparinised vacutainers and were transported to the laboratory in ice cold chamber. Samples were cultured within 24 hours of blood collection in order to get good metaphase spreads of chromosomes. The cytogenetic study in these goats was carried out by whole blood short-term lymphocyte culture technique as given by Moorehead et al., (1960), with appropriate modifications as required.

\section{Parameters considered for study}

\section{Number, morphology and morphometry of chromosomes}

A minimum of 10 good quality metaphase spreads were considered to minimize sampling error. Chromosomes were identified and classified as per the International System for the Cytogenetic Nomenclature of Domestic Animals (ISCNDA, 1990). Homologous pairs were identified and karyotyped based on size and structure of chromosomes using IKARYOS software. Karyotypes established were used for the measurement of length of chromosomes.

\section{Mitotic drive (MD) and Mitotic index (MI)}

The mitotic drive was estimated as the percentage of number of cells in metaphase and number of lymphoblast to the total number of lymphocytes proliferated. Mitotic index was calculated as the percentage of number of cells in metaphase to the total lymphocyte proliferated.

\section{Relative length (RL)}

RL of the individual chromosome was the ratio of length of the chromosome to the total 
length of genome including $\mathrm{X}$ chromosome and multiplied by 100 .

\section{Arms ratio}

AR was calculated as ratio of length of long $\operatorname{arm}(q)$ to the length of short arm (p).

\section{Centromeric index}

CI was calculated as the ratio of length of short arm (p) to the total length of chromosome $(p+q)$ and multiplied by 100 .

\section{Morphological index}

It was calculated by dividing the total length of chromosome $(p+q)$ by the arms ratio and multiplied by 100 .

\section{Idiogram}

Idiogram was constructed by taking the chromosome number on $\mathrm{X}$-axis and mean relative lengths of individual pairs of chromosomes on the Y-axis (Fig. 3).

\section{Results and Discussion}

\section{Mitotic drive and mitotic index}

The mean mitotic drive was found to be $57.95 \pm 1.16$ and $60.2 \pm 2.38$ per cent in males and females, respectively. Similar result $(64.96 \%)$ was observed in local goats of Karnataka by Jayshree et al., (2014) and Kasabe et al., (2009) reported mean mitotic drive of $51.22 \pm 0.65$ and $47.94 \pm 0.94$ per cent in females and males, respectively in Berari goats. The mitotic index was $8.75 \pm 0.73$ and $9.05 \pm 0.64$ per cent in males and females, respectively. Similar result $(10.62 \%)$ was observed in local goats of Karnataka by Jayshree et al., (2014) and Kasabe et al., (2009) reported mean mitotic index as $6.59 \pm 0.58$ and $5.29 \pm 0.85$ per cent in females and males, respectively in Berari goats.

\section{Number and morphology of chromosomes}

All the metaphase spreads examined in this study had a diploid number (2n) of 60 chromosomes with 58 autosomes and two sex chromosomes (XY in males and XX complement in females) (Fig. 1 and 2). All the 58 autosomes were found to be acrocentric, $\mathrm{X}$-chromosome was observed to be the longest acrocentric and the $\mathrm{Y}$ chromosome was sub metacentric in appearance, which was confirmed by arms ratio, centromeric index and morphological index. Similar results with regard to number and morphology of autosomes were reported in many Indian goat breeds like Kanniadu (Saravanan et al., 2006), Berari (Kasabe et al., 2009), Mahabubnagar (Ekambaram et al., 2011), Karnataka local goats (Jayashree, 2014), Sangamneri (Bhagat et al., 2014), Osmanabadi and Boer bucks (Kokani et al., 2018) and in native Black Bengal goats (Banani et al., 2018). In contradiction to the present findings, the autosomes were found to be telocentric in Tehran goats (Khavary, 1973), Korean local goats (Yeo, 1984) and in Ganjam and Black Bengal goats (Pattnayak and Patro, 1986).

The acrocentric nature of $\mathrm{X}$-chromosome in the present study was in agreement with the reports of Korean native goats (Yeo, 1984), Berari (Kasabe et al., 2009), Mahabubnagar (Umadevi et al., 2011), Karnataka local goats (Jayashree, 2014), Sangamneri (Bhagat et al., 2014), Osmanabadi and Boer bucks (Kokani et al., 2018) and Native Black Bengal (Banani et al., 2018). In contradiction to the present findings, X-chromosome was reported to be telocentric in Tehran goats (Khavary, 1973).

Y-chromosome was found to be sub metacentric in the present study, however it was metacentric in morphology and smallest in the complement as observed by Khavary (1973), Jayashree (2014) in Karnataka local goats and Bhagat et al., (2014) in Sangamneri 
goats. Bunch et al., (1977) reported that the Y- chromosome may be metacentric or submetacentric but not acrocentric. Umadevi et al., (2011) observed that the Y chromosome appeared to be smallest and dot like in Mahabubnagar local goat breed and Black Bengal goat breeds, respectively. In Osmanabadi and Boer bucks, Y chromosome was the smallest dot like in majority of the metaphase examined and in few metaphases it was found to be sub metacentric in morphology (Kokani et al., 2018). In Black Bengal goats, Y-chromosome was found to be smallest, dot like structure and suspected to be sub-metacentric (Banani et al., 2018).

\section{Relative length}

In Jayawadagi goats, the mean relative length of autosomes varied from $1.81 \pm 0.08$ to $4.79 \pm 0.09$ per cent in females and $1.46 \pm 0.17$ to $4.11 \pm 0.44$ per cent in males. The relative length of $\mathrm{X}$ - chromosome in females was $5.24 \pm 0.19$ and that in males was $4.13 \pm 0.63$, whereas Y-chromosome had a relative length of $1.40 \pm 0.24$. The mean relative length of $X-$ chromosome was highest in comparison to that of the autosomes. Analysis of relative length data revealed a non significant difference in the mean relative length of the chromosomes between males and females.

In Kanniadu goats, the relative lengths of autosomes ranged from 1.61 to 5.49 per cent (Saravanan et al., 2006). The least square means for relative length of autosomes in uni, bi and multicolored Mahabubnagar goats ranged from 1.997 to $4.742,2.050$ to 5.065 and 2.041 to 4.672 per cent, respectively with no significant difference between them (Umadevi et al., 2011). The mean relative length $(\%)$ of autosomes varied from $1.65 \pm 0.11$ to $5.69 \pm 0.18$ in males and $1.68 \pm 0.13$ to $5.26 \pm 0.16$ in females and significant differences in relative length was observed between the sexes in $1^{\text {st }}, 16^{\text {th }}, 17^{\text {th }}$, $19^{\text {th }}, 20^{\text {th }}, 21^{\text {st }}, 23^{\text {rd }}, 24^{\text {th }}$ and $25^{\text {th }}$ pair of autosomes (Jayashree, 2014). The relative length of autosomes varied from 1.79 to 5.19 per cent in females and in males from 1.78 to 5.25 per cent in Black Bengal goats (Banani et al., 2018).

The relative length of $\mathrm{X}$ - chromosome was 5.1 to 5.8 per cent in Ganjam goats (Pattnanayak and Patre, 1986). The relative length of $\mathrm{X}$ chromosome in Mahabubnagar goats was 5.86 \pm 0.08 (Ekambaram et al., 2011) and 5.16 (Umadevi et al., 2011), in local goats of Karnataka it was $6.05 \pm 0.15$ in females and 6.28 \pm 0.31 in males (Jayashree, 2014). The relative length of $X$ chromosome was found to be $5.95 \pm 0.05$ in males and $5.57 \pm 0.05$ in females of Black Bengal goats (Banani et al., 2018). The Y chromosome had a relative length of $1.36 \pm 0.05$ percent in Mahabubnagar goats (Ekambaram et al., 2011), $1.42 \pm 0.13$ per cent in local goats of Karnataka (Jayashree, 2014) and 1.47 \pm 0.03 per cent in Black Bengal goats (Banani et al., 2018). Whereas, Umadevi et al., (2011) reported 1.96 per cent in Mahabubnagar goats.

In this study, the mean arms ratio of Jayawadagi goats was 3.09 and arms ratio of all Y-chromosomes was found to be more than 1 and lesser than 7, mean centromeric index was 30.00 and centromeric index of all $\mathrm{Y}$ chromosomes was found to be more than 12.5 and lesser than 50.0, and average morphological index of $\mathrm{Y}$-chromosome was 712.49 which was lesser than the mean genome length of 1422.8. All these parameters confirm the sub metacentric nature of $\mathrm{Y}$ chromosome in Jayawadagi goats. However, Umadevi et al., (2011) reported arms ratio as 1.68 per cent (1.08 to 4.19$)$, centromeric index as 39.22 per cent, morphological index as 214.00 and genome length as $321.75 \mathrm{~mm}$ in Mahabubnagar goats. 
Table.1 Least squares means of relative length (\%) of Autosomes and Sex Chromosomes of Jayawadagi goats

\begin{tabular}{|c|c|c|}
\hline Chromosome number & Female & Male \\
\hline 1 & $4.79 \pm 0.09$ & $4.11 \pm 0.44$ \\
\hline 2 & $4.47 \pm 0.08$ & $3.78 \pm 0.41$ \\
\hline 3 & $4.34 \pm 0.08$ & $3.66 \pm 0.40$ \\
\hline 4 & $4.27 \pm 0.07$ & $3.59 \pm 0.39$ \\
\hline 5 & $4.20 \pm 0.07$ & $3.50 \pm 0.38$ \\
\hline 6 & $4.11 \pm 0.05$ & $3.43 \pm 0.37$ \\
\hline 7 & $3.90 \pm 0.05$ & $3.33 \pm 0.36$ \\
\hline 8 & $3.84 \pm 0.04$ & $3.24 \pm 0.35$ \\
\hline 9 & $3.76 \pm 0.05$ & $3.11 \pm 0.35$ \\
\hline 10 & $3.63 \pm 0.04$ & $2.99 \pm 0.34$ \\
\hline 11 & $3.54 \pm 0.02$ & $2.86 \pm 0.31$ \\
\hline 12 & $3.37 \pm 0.04$ & $2.77 \pm 0.29$ \\
\hline 13 & $3.31 \pm 0.03$ & $2.68 \pm 0.28$ \\
\hline 14 & $3.24 \pm 0.03$ & $2.56 \pm 0.25$ \\
\hline 15 & $3.18 \pm 0.03$ & $2.48 \pm 0.24$ \\
\hline 16 & $3.13 \pm 0.04$ & $2.42 \pm 0.24$ \\
\hline 17 & $3.01 \pm 0.04$ & $2.35 \pm 0.23$ \\
\hline 18 & $3.01 \pm 0.04$ & $2.31 \pm 0.23$ \\
\hline 19 & $2.90 \pm 0.04$ & $2.23 \pm 0.23$ \\
\hline 20 & $2.82 \pm 0.04$ & $2.15 \pm 0.23$ \\
\hline 21 & $2.75 \pm 0.06$ & $2.11 \pm 0.23$ \\
\hline 22 & $2.68 \pm 0.07$ & $2.04 \pm 0.22$ \\
\hline 23 & $2.63 \pm 0.06$ & $1.99 \pm 0.21$ \\
\hline 24 & $2.57 \pm 0.07$ & $1.90 \pm 0.20$ \\
\hline 25 & $2.48 \pm 0.05$ & $1.90 \pm 0.20$ \\
\hline 26 & $2.43 \pm 0.05$ & $1.86 \pm 0.21$ \\
\hline 27 & $2.32 \pm 0.05$ & $1.72 \pm 0.19$ \\
\hline 28 & $2.16 \pm 0.06$ & $1.62 \pm 0.17$ \\
\hline 29 & $1.81 \pm 0.08$ & $1.46 \pm 0.17$ \\
\hline $\mathbf{X}$ & $5.24 \pm 0.19$ & $4.13 \pm 0.63$ \\
\hline $\mathbf{Y}$ & & $1.40 \pm 0.24$ \\
\hline
\end{tabular}


Table.2 Arms ratio, centromeric index and morphological index of Y chromosome of Jayawadagi goats

\begin{tabular}{|c|c|c|c|c|c|c|}
\hline $\begin{array}{c}\text { Animal } \\
\text { number }\end{array}$ & $\begin{array}{c}\text { Short } \\
\text { arm (p) } \\
\text { pixels }\end{array}$ & $\begin{array}{c}\text { Long } \\
\text { arm (q) } \\
\text { pixels }\end{array}$ & $\begin{array}{c}\text { Total } \\
\text { Length } \\
\text { (p+q) pixels }\end{array}$ & $\begin{array}{c}\text { Arms } \\
\text { Ratio }\end{array}$ & $\begin{array}{c}\text { Centromeric } \\
\text { Index }\end{array}$ & $\begin{array}{c}\text { Morphological } \\
\text { Index }\end{array}$ \\
\hline $\mathbf{1}$ & 3 & 18 & 21 & 6.00 & 14.29 & 174.00 \\
\hline $\mathbf{2}$ & 5 & 21 & 26 & 4.20 & 19.23 & 258.57 \\
\hline $\mathbf{3}$ & 7 & 8 & 15 & 1.14 & 46.67 & 882.00 \\
\hline $\mathbf{4}$ & 7 & 9 & 16 & 1.29 & 43.75 & 1546.22 \\
\hline $\mathbf{5}$ & 6 & 17 & 23 & 2.83 & 26.09 & 701.65 \\
\hline
\end{tabular}

Figure.1 Mitotic-metaphase spread of Jayawadagi buck

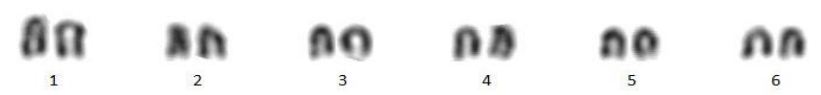

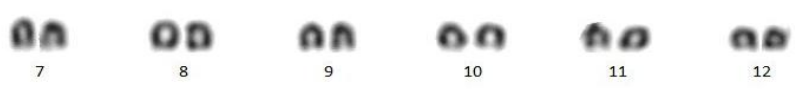
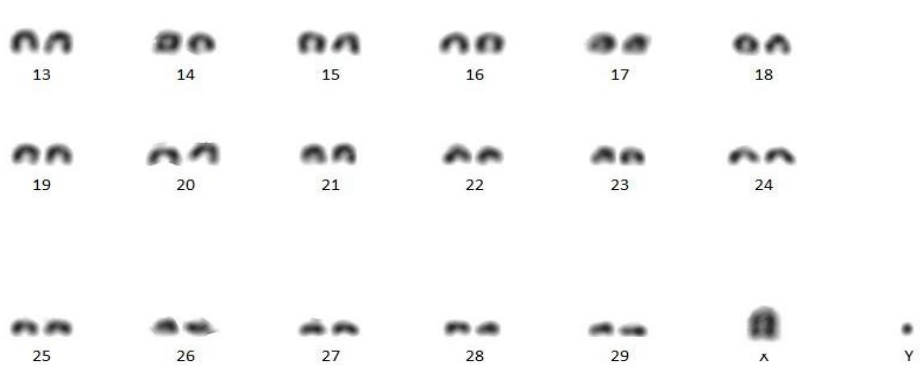

Figure.2 Mitotic-metaphase spread of Jayawadagi doe

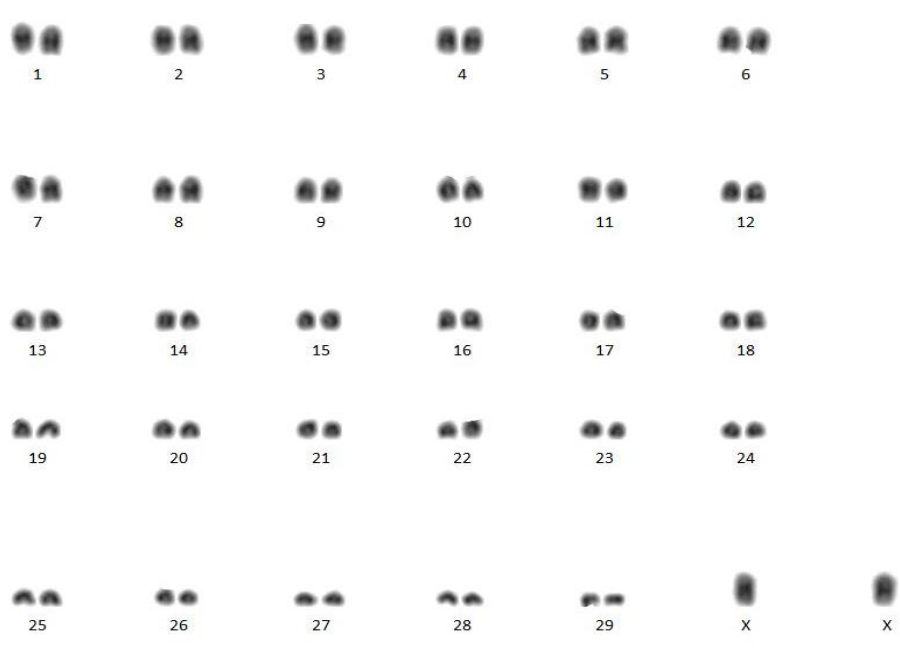


Figure.3 Idiogram based on relative length of chromosomes of Jayawadagi goats

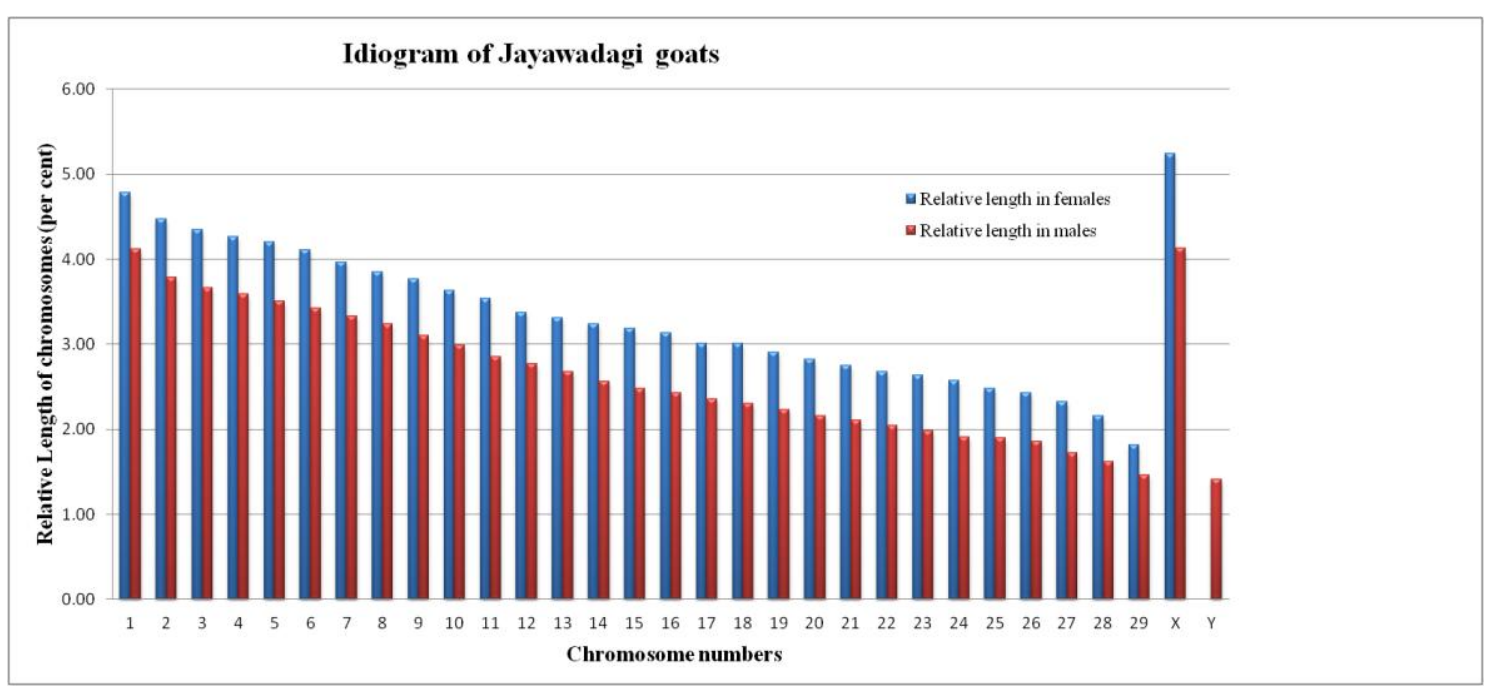

In conclusion, the present karyological profiling of Jayawadagi goats revealed chromosomal compliment which evinces the absence of any kind of chromosomal abnormalities. This normal chromosome compliment reveals the prospective status of Jayawadagi goats for reproductive health and fertility. This information will benefit in goat breeding program aiming at enhancing meat production, disease resistance and adaptation to environmental stress.

\section{References}

Anonymous, 2019. 20 ${ }^{\text {th }}$ Quinquennial Indian Livestock census, Department of Animal Husbandry, Dairying \& Fisheries, Ministry of Agriculture, New Delhi.

Banani, M., Ravindra, K., Nandani, K. and Nishant, P., 2018. Standardized Karyotype and Idiogram of Native Black Bengal Goats. International Journal of Current Microbiology and Applied Sciences, Special Issue-7 pp. 510-517.

Basumatary, R., 2003. Cytogenetic studies on cows with fertility disorder. M.V.Sc thesis submitted to Assam agricultural
University, Guwahati, Assam, India. Bhagat, S. B., Khade, A. S., Khade S. B., Pawar V. D., Umrikar U. D., Sawane M. P. and Doiphode, A. Y., 2014. Karyological evaluation of Sangamneri goat. J. Bombay Vet. College. 21(1): 5053.

Ekambaram, Ramesh Gupta, B. R., Prakash, M. G., Sudhaker, K. and Reddy, V. R., 2011. Cytogenetic characterization of Mahabubnagar goats. Tamil Nadu J. Veterinary and Animal Science, 7 (3): 157-163.

ISCNDA, 1990. International System for Cytogenetic Nomenclature of Domestic Animals. In: Proceeding of the Second International Conference for the Standardization of Domestic Animal Karyotype. Paris (1989). Cytogenetics and Cell Genetics, 53: 665-679.

Jayashree R., Jayashankar M. R., Nagaraja C. S., Cauveri D., Satyanarayana, K. and Shrikrishna, I., 2014. Karyological studies in goats of Karnataka. Frontier J. Vet. Anim. Sci, 3(2): $141-144$.

Kasabe, S.S., Ali, S. Z., Sawane, M. P. and Kuralkar, S. V., 2009. Chromosome morphology of Berari goats with special reference to mitotic drive and mitotic 
index. Indian Journal of Small Ruminants, 15(2): 971-985.

Khavary, H., 1973. A proposed method for classifying chromosomes of Capra hircus. Journal of Veterinary Faculty, University of Tehran, 29: 69-71.

Kokani, S. C., Pawar, V. D., Sawane, M. P., Chopade, M. M. and Khade, S. B., 2018. Cytogenetic Analysis of Osmanabadi and Boer Breeding Bucks Breeds. International Journal of Current Microbiology and Applied Sciences, 7(6): 543-547.

Moorehead, P. S., Nowell, P. C., Mellman, W. J., Battips, D. M. and Hungerford, D.A., 1960. Chromosome preparation of leucocytes cultured from human peripheral blood. Experimental Cell Research, 20: 613-616.

Pattanayak, G. R. and Patro, B. N., 1986. Chromosomes of Ganjam, Black Bengal and F1 (Gangam x Black Bengal) goats. Indian Journal of Heredity, 18: 37-47.
Saravanan, R. Karthickeyan, S. M., Balasubramanyam. D., Deshpande, A. D., Gopu, P. and Thara, S., 2006. Karyological studies in Kanni Adu breed of goats. Indian Journal of Small Ruminants, 16-20.

Stranzinger, G. F. and Fechheimer, N. S., 1989. Standardization of banded chromosomes in farm animals: Present stage, ISCN (1985) standard and further developments. In proceedings of the 8th European colloquium on cytogenetics of domestic animals, Bristol. 1-18.

Umadevi, P., Ramesh G., Sakunthala Devi, B. and Dhana Lakshmi, K., 2011, Cytogenetic characterization of Mahabubnagar goats, Tamil Nadu. J. Veterinary and Animal Sciences, 7 (6): 268-276.

Yeo. J. S., 1984. Chromosome analysis of Korean native goat. Korean Journal of Animal Sciences, 26: 231-232.

\section{How to cite this article:}

Basavraj Inamdar, R. Nagaraja, S. Naveen Kumar, H. M. Yathish, G. S. Naveen Kumar, K. V. Sudha and Rashmi, S. 2020. Karyotype and Idiogram of Jayawadagi Goats of Karnataka. Int.J.Curr.Microbiol.App.Sci. 9(07): 3373-3380. doi: https://doi.org/10.20546/ijcmas.2020.907.394 